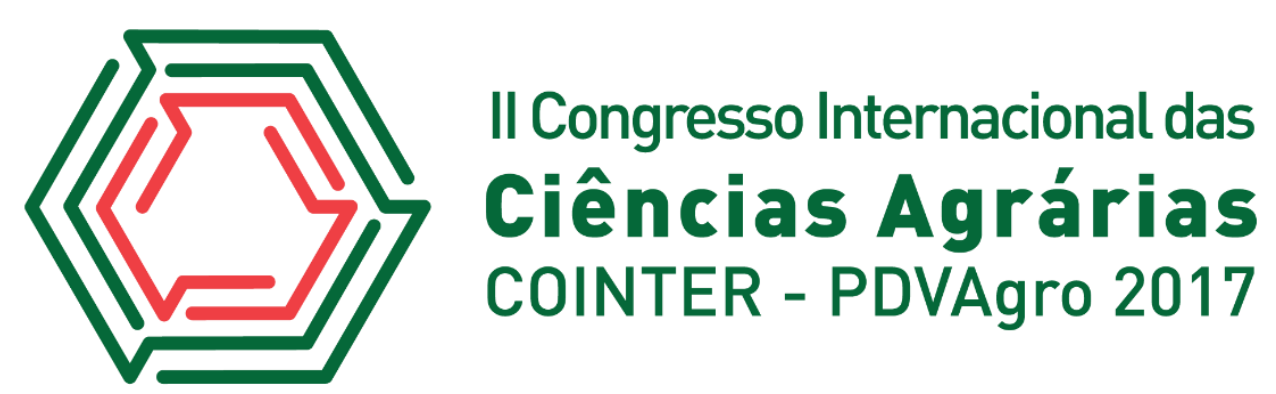

\title{
AVALIAÇÃO DE RÓTULOS DE CREMES DE LEITE COMERCIALIZADOS NO MUNICÍPIO DE GARANUNS - PE
}

\author{
Apresentação: Pôster \\ Krause Gonçalves Silveira Albuquerque ${ }^{1}$; Layra Catarina de Almeida Xavier ${ }^{2}$; Gerla \\ Castello Branco Chinelate ${ }^{3}$
}

\section{Introdução}

Dentre os diversos alimentos de origem animal o leite destaca-se pelo seu amplo consumo, que é atribuído por MACHADO et al (2014) pelo fato deste ser um dos poucos produtos que é consumido por pessoas de todas as classes econômicas. Possui largo emprego nas indústrias, sobretudo na indústria alimentícia, onde é utilizado como matéria prima para a produção de diversos derivados. Dentre estes existe o creme de leite que, de acordo com a Portaria $n^{\text {o }} 146$ de 1996 do MAPA (BRASIL, 1996), é definido como um produto lácteo relativamente rico em gordura retirada do leite por procedimento tecnologicamente adequado que apresenta a forma de uma emulsão de gordura em água.

A partir da necessidade da produção em grandes escalas e o estabelecimento de um controle de qualidade dos produtos desenvolvidos criou-se o sistema de rotulagem. A rotulagem trata-se de toda inscrição, imagem, legenda ou matéria descritiva ou gráfica, escrita, impressa ou gravada em relevo ou colocada sobre o alimento, segundo a resolução de 20 de setembro de 2002 RDC no 259 (BRASIL, 2002). Os dados apresentados precisam ser claros, pois possuem a finalidade de auxiliar os consumidores na hora da compra, informando sua especificação de qualidade, composição, quantidade e características (DIAS et al., 2008).

Além da definição de rotulagem estabelecida pela resolução RDC no 259 , de 20 de setembro de 2002 (BRASIL, 2002) existe também a rotulagem nutricional, definida pelas resoluções de $n^{\circ}$ 359 e no 360 de 2003 (BRASIL, 2003a; BRASIL, 2003b). Estas estabelecem a obrigatoriedade ou não de determinadas informações em rótulos de alimentos. Conforme suas indicações a rotulagem

\footnotetext{
${ }^{1}$ Eng. de Alimentos, UFRPE-UAG, albuquerque.k.g.s@gmail.com

${ }^{2}$ Eng. de Alimentos, UFRPE-UAG, layracatarina@gmail.com

${ }^{3}$ Dra. em Biotecnologia, UFRPE-UAG, gerla.chinelate@yahoo.com.br
} 
nutricional deve conter as informações do alimento sobre suas propriedades típicas quanto às proteínas, fibras, gorduras, valor energético, carboidratos, minerais e vitaminas. E obrigatoriamente informar a quantidade de gorduras trans presente no produto. $\mathrm{O}$ presente trabalho tem por finalidade a verificação da rotulagem de amostras de cremes de leite comercializados no município de Garanhuns-PE, analisando-se sua regularidade perante a legislação vigente.

\section{Fundamentação Teórica}

Sendo o rótulo um instrumento de auxílio ao consumidor, cabe a este analisá-lo. Entretanto, é possível observar que muitas vezes não se faz uso da rotulagem no momento da aquisição dos alimentos. O hábito de leitura de rótulos é uma prática que deve ser exercida pelo consumidor no momento da aquisição de produto alimentício. Contudo, existe claramente um déficit neste aspecto, principalmente nos consumidores do sexo masculino, nos quais 69,1\% afirmam que "Raramente" ou "Nunca" leem os rótulos dos alimentos antes de compra-los (Machado et al., 2014).

O estudo e avaliação de rotulagens de alimentos é um tema que já possui expressividade na literatura, onde a partir desta é possível notar que existem diversas irregularidades recorrentes, as quais podem também serem atribuídas ao consumidor uma vez que existe um descaso por parte deste em relação a averiguação das informações expressas no rótulo dos produtos. Estudos desenvolvidos por Grandi e Rossi (2010) em produtos lácteos fermentados e por Sálvio et al. (2013) e Araújo et al. (2015), em leite UHT, evidenciaram problemas em rotulagens de alimentos lácteos industrializados, além disso o trabalho realizado por Aquino et al (2017) verificaram irregularidades especificamente em cremes de leite.

\section{Metodologia}

A verificação dos rótulos de cremes de leite foi realizada a partir de amostras identificadas em diferentes supermercados da cidade de Garanhuns. Foram coletadas 10 marcas de cremes de leite aleatoriamente e realizada a análise de suas rotulagens.

Para a identificação das embalagens avaliadas, foram atribuídas letras consecutivas e arbitrariamente. As analises foram realizadas de acordo com as informações estabelecidas pelas RDC n 359/03 (BRASIL, 2003a), 360/03 (BRASIL, 2003b) e 259/02 (BRASIL, 2002). Em relação aos paramentos avaliados, levaram-se em consideração 11 critérios obrigatórios e 12 critérios 
pertinentes a informação nutricional metodologia também utilizada por Aquino et al (2017). Os critérios obrigatórios considerados são: Lista de Ingredientes, Medida Caseira, Identificação da Origem, Denominação de Venda do Alimento, Conteúdo Líquido, Identificação do Lote, Data de Fabricação, Prazo de Validade, Conservação do Produto, Ausência de Glúten; Nome do País de Origem. Foram marcados com "X" os critérios que estavam de acordo e com “_" os que não estavam ou não foram apresentados. Os critérios referentes à rotulagem nutricional: Valor Energético (Kcal), Carboidratos (g), Porção (g), Sódio (mg), Cálcio (mg), Proteínas (g), Gorduras Totais (g), Gorduras Saturadas (g), Gorduras Trans (g), Ferro, Colesterol (mg), Fibra Alimentar (g).

\section{Resultados e Discussão}

Os resultados obtidos no que se referem as informações de critérios obrigatórios não nutricionais estão expressões na Tabela 1.

Tabela 1. Informações obrigatórias nos rótulos dos cremes de leite comercializados em Garanhuns-PE

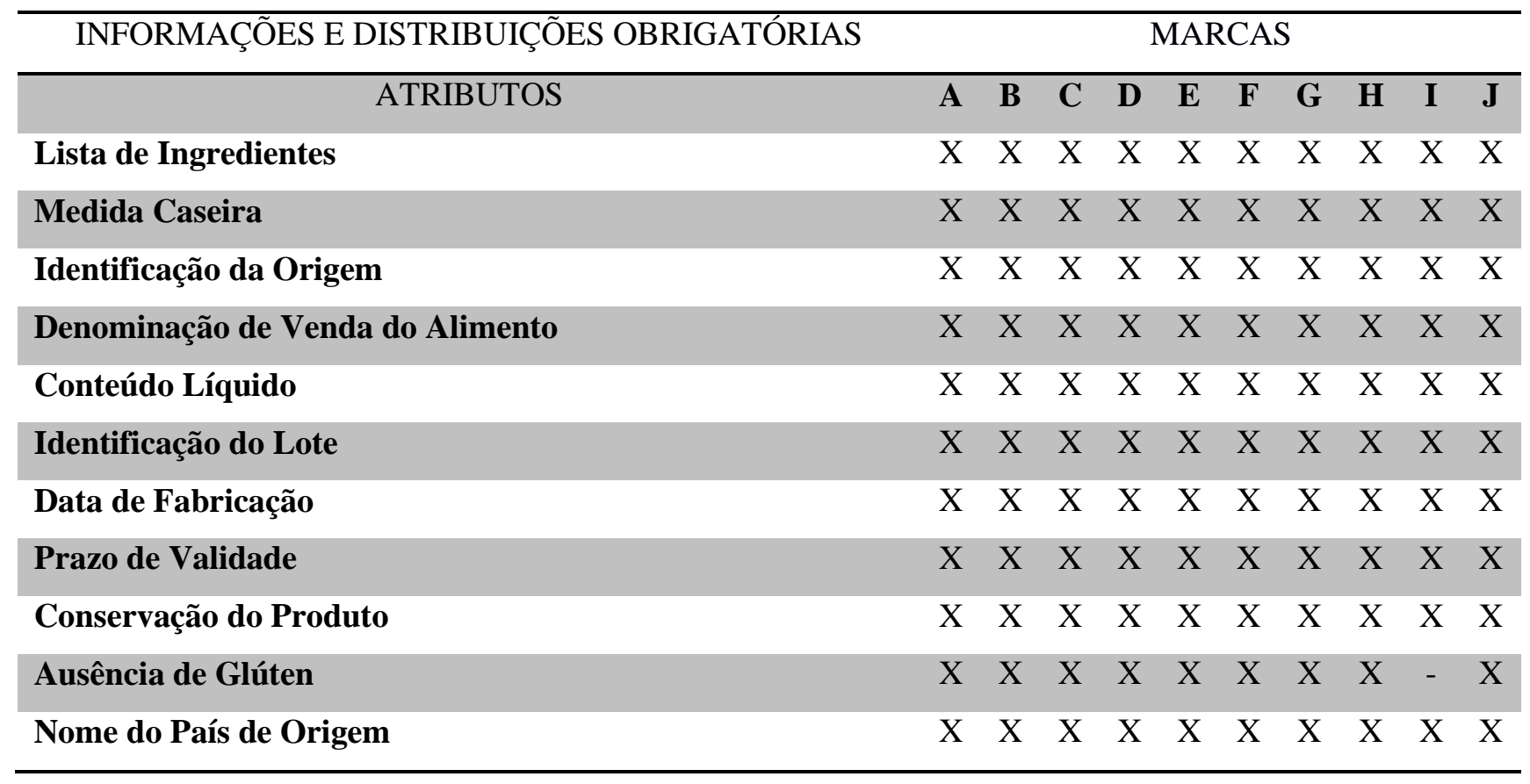

Onde é possível visualizar que com exceção da marca I no quesito conservação do produto $100 \%$ das marcas em $100 \%$ dos quesitos estão dentro dos parâmetros estabelecidos pela legislação através da Resolução RDC nº 259 de 20 de setembro de 2002 (BRASIL, 2002).

Em relação as informações nutricionais, os dados obtidos estão expressos na Tabela 2, 
Tabela 2. Informações nutricionais nos rótulos dos cremes de leite comercializados em Garanhuns-PE

\begin{tabular}{lcccccccccc}
\hline \multicolumn{1}{c}{ INFORMAÇÃO NUTRICIONAL } & \multicolumn{1}{c}{ MARCAS } \\
\hline \multicolumn{1}{c}{ ATRIBUTOS } & A & B & C & D & E & F & G & H & I & J \\
Valor energético (Kcal) & 25 & 27 & 27 & 23 & 27 & 30 & 26 & 29 & 29 & 32 \\
Carboidratos (g) & 0,6 & 0,6 & 0,6 & 0 & 0,7 & 0 & 0,6 & 0 & 0,9 & 0 \\
Porção (g) & 15 & 15 & 15 & 14 & 15 & 15 & 15 & 15 & 15 & 15 \\
Sódio (mg) & 12 & 8 & 8 & 7,1 & 10 & 0 & 12 & 10 & 8 & 10 \\
Cálcio (mg) & - & - & - & - & - & 11 & - & 13 & 5 & - \\
Proteínas (g) & 0 & 0,3 & 0,3 & 0 & 0 & 0 & 0 & 0,5 & 0,6 & 0 \\
Gorduras Totais (g) & 2,6 & 2,5 & 2,5 & 2,6 & 2,6 & 3 & 2,6 & 3 & 2,8 & 3 \\
Gorduras Saturadas (g) & 1,6 & 1,8 & 1,8 & 1,6 & 1,5 & 1,8 & 1,6 & 1,3 & 1,8 & 1,7 \\
Gorduras Trans (g) & 0 & 0 & 0 & 0 & 0 & 0 & 0 & 0 & 0 & 0 \\
Ferro & - & - & - & - & - & - & - & - & - & - \\
Colesterol (mg) & - & - & - & - & 6,6 & - & - & - & - & - \\
Fibra Alimentar (g) & 0 & 0 & 0 & - & 0 & 0 & 0 & 0 & 0 & - \\
\hline
\end{tabular}

Analisou-se que é possível visualizar segundo a Resolução no 359 e 360 de 2003 que com exceção da marca D no que diz respeito ao teor de fibras alimentícias $100 \%$ das marcas estudadas apresentam as informações exigidas pela legislação. Dado contrário ao apresentado por Aquino et al (2017), onde ao estudar as marcas de cremes de leite comercializadas em Pau dos Ferros - RN observou que $28,57 \%$ das amostras não apresentaram o teor de gorduras trans.

Entretanto ainda em comparação com o mesmo estudo é possível identificar dados similares no que diz respeito a apresentação dos teores de colesterol nos rótulos estudados. Aquino et al (2017) identificou em seu estudo que $28.57 \%$ (5 das 7 marcas estudadas) das amostras não apresentaram o valor deste. Enquanto no presente estudo obteve-se apenas $10 \%$ (1 amostra) das amostras com o valor deste composto expresso.

No que diz respeito aos teores de cálcio e ferro identificou-se respectivamente valores de $30 \%$ e $100 \%$ das amostras não apresentam os teores. Isso se dá pela não obrigatoriedade da expressão dos teores de colesterol, cálcio e ferro nos rótulos.

A partir dos estudos de rotulagens de lácteos desenvolvidos por Grandi e Rossi (2010) em produtos lácteos fermentados e por Sálvio (2013) e Araújo et al. (2015), em leite UHT e por Aquino et al (2017) em cremes de leite é possível identificar a existência de irregularidades, as quais são apresentadas em produtos com carimbo tanto do Sistema de Inspeção Federal (SIF) como também os Serviços de Inspeção Estaduais (SIE). 


\section{Conclusões}

A partir do levantamento realizado, identificou-se irregularidades em apenas duas das dez marcas estudadas. Indicando que oito das marcas de creme de leite comercializadas na cidade de Garanhuns - PE contém todas as informações exigidas pela legislação brasileira.

O presente trabalho vem contribuir na discursão sobre a rotulagem de produtos lácteos e sua adequação aos parâmetros estabelecidos pela legislação brasileira. Através do estudo realizado é possível identificar fragilidades nos sistemas de inspeção e contribuir com a sua constante melhora.

\section{Referências}

AQUINO, C. E. F.; MORAIS, M. C. G.; OLIVEIRA, R. M. S.; ALMEIDA, F. L. C.; OLIVEIRA, E.N. A.; OLIVEIRA, S. N. Avaliação da rotulagem de cremes de leite comercializados na cidade de Pau dos Ferros-RN. Revista Brasileira de Agrotecnologia, Brasil, v. 7, n. 1, 2017.

BRASIL. Portaria n 146 de 07 de março de 1996. Aprovar o regulamento técnico de identidade e qualidade de produtos lácteos. Diário Oficial da União, Brasília, 11 Mar. 1996.

BRASIL. Resolução RDC n 360, de 23 de dezembro de 2003. Regulamento Técnico sobre Rotulagem Nutricional de Alimentos Embalados, tornando obrigatória a rotulagem nutricional. Diário Oficial da União, Brasília, 26 Dez. 2003 b.

BRASIL. Resolução RDC n 259, de 20 de setembro de 2002. Aprovar o Regulamento Técnico sobre Rotulagem de Alimentos Embalados. Diário Oficial da República Federativa do Brasil, Brasília, 23 Set. 2002.

GRANDI, A.Z.; ROSSI, D.A. Avaliação dos itens obrigatórios na rotulagem nutricional de produtos lácteos fermentados. Avaliação dos itens obrigatórios na rotulagem nutricional de produtos lácteos fermentados. Rev. Inst. Adolfo Lutz, 69, 1, 62-68, 2010.

MACHADO, W. R. C.; LEUNG, R.; LEITE, M. A. G. Percepção do consumidor sobre rotulagem de produtos lácteos industrializados. Revista de Engenharia e Tecnologia, V. 6, No. 2, 2014 SALVIO, B.P.; SOUZA, C.R.; BETI, G.C.B. Análise de rotulagem de leite integral UHT comercializado no município de Promissão-SP. Rev. Cient. Unisalesiano, 4, 8, 2013.

BRASIL. Resolução RDC n 359, de 23 de dezembro de 2003. Regulamento Técnico de Porções de Alimentos Embalados para fins de Rotulagem Nutricional. Diário Oficial [da] União, Brasília, 26 Dez. 2003a. 